Article

\title{
Wind Power Economic Feasibility under Uncertainty and the Application of ANN in Sensitivity Analysis
}

\author{
Paulo Rotela Junior ${ }^{1, * \mathbb{C}}$, Eugenio Fischetti ${ }^{1}$, Victor G. Araújo ${ }^{1}$, Rogério S. Peruchi ${ }^{1}{ }^{\mathbb{C} \text {, }}$ \\ Giancarlo Aquila ${ }^{2} \mathbb{D}$, Luiz Célio S. Rocha ${ }^{3} \mathbb{D}$ and Liviam S. Lacerda ${ }^{1}$ \\ 1 Department of Production Engineering, Federal University of Paraíba, João Pessoa 58051-970, Brazil; \\ eugenioasfischetti@gmail.com (E.F.); victor.g.araujo10@gmail.com (V.G.A.); \\ rogerioperuchi@gmail.com (R.S.P.); soaresliviam@gmail.com (L.S.L.) \\ 2 Institute of Industrial Engineering and Management, Federal University of Itajubá, Itajubá 37500-000, Brazil; \\ giancarlo.aquila@yahoo.com \\ 3 Department of Management, Federal Institute of Education, Science and Technology Northern of Minas \\ Gerais, Almenara 39900-000, Brazil; luizrochamg@hotmail.com \\ * Correspondence: paulorotela@ct.ufpb.br
}

Received: 23 April 2019; Accepted: 21 May 2019; Published: 14 June 2019

\begin{abstract}
Wind power has grown popular in past recent years due to environmental issues and the search for alternative energy sources. Thus, the viability for wind power generation projects must be studied in order to attend to the environmental concerns and still be attractive and profitable. Therefore, this article aims to perform a sensitive analysis in order to identify the variables that influence most in the viability of a wind power investment for small size companies in the Brazilian northeast. For this, a stochastic analysis of viability through Monte Carlo Simulation (MCS) will be made and afterwards, Artificial Neural Networks (ANN) models will be applied for the most relevant variables identification. Through the sensitivity, it appears that the most relevant factors in the analysis are the speed of wind, energy tariff and the investment amount. Thus, the viability of the investment is straightly tied to the region where the wind turbine is installed, and the government incentives may allow decreasing in the investment amount for wind power. Based on this, incentives programs for the production of clean energy include cheaper purchase of wind turbines, lower taxing and financing rates, can make wind power more profitable and attractive.
\end{abstract}

Keywords: economic feasibility; net present value; artificial neural networks; wind power; sensitivity analysis

\section{Introduction}

Since the 1960s and affected by the oil crisis episode, the situation of fossil resource level, which is the main source of energy, has become alarming. Consequently, at the same period, the renewable energy sector attracted more investment and greater efforts for technological progress in order to develop an alternative to fossil fuels [1,2].

Rocha et al. [3] stated that renewable energy refers to the form of energy that occurs naturally in a continuous and infinite way. It is known that many types of energy fall into this definition, such as those that comes directly from the sun (for instance, photovoltaic energy), wind, tides and waves.

The popularity of wind power has increased due to environmental problems, fossil fuels price volatility, as well as the risks and geopolitical uncertainties related to the dependence on imports of these fossil resources [1,4,5]. In addition, Mohammadi and Mehrpooya [6] state that the global fossil resources consumption growth, results in several challenges because fossil fuels are exhaustible in the near future, and their combustion leads to environmental problems such as the ozone layer 
depletion, acid rain, climate change, etc. Thus, new energy sources are needed in order to overcome these problems.

According to Aquila et al. [7], the renewable energy market is expanding and regulatory changes have influenced the energy sector in Brazil. In 2012, the Electric Power Regulatory Agency (ANEEL), through resolution number 482/2012, introduced a net metering system aiming to promote microgeneration from RES. The authors also discuss the need for studies on microgeneration feasibility and as well as comparisons between different regions. Wong et al. [8] adds that policies related to renewable energy should encourage investors to provide clean energy to consumers and thus create a model of sustainable development.

According to the Energy Research Company [9], Brazil has $41.2 \%$ of renewable energy in its energy matrix, $64 \%$ of which is hydroelectric. For that reason, Brazil shows a strong dependence on hydropower. However, since 2011, wind energy has been presenting a favorable growth scenario in Brazil. Nowadays, wind energy has a prominence at the Brazilian electricity market. Wind power adoption has increased in Brazil due to the crisis of electricity supply, environmental attractiveness, adoption of incentive programs by the Brazilian government, and the actions to structure a regulatory framework for the production of electricity from RES (renewable energy sources) [10].

In 2014, a drought threatened the supply of electricity in Brazil. Thus, in order to mitigate the hydrological risk in the country, the use of other renewable energy sources had been stimulated [1]. In addition, according to Rocha et al. [3], Brazil has high wind potential, especially in the northeast region, which can be proven by the numerous farms that have been installed in the region.

For Silva et al. [10], the electricity supply crisis and the incentives of the Brazilian government are characteristics that can attract investors to the wind energy generation, thus making it possible to take advantage of Brazil's high wind potential. It is evident that there is a growing trend in the use of Brazilian wind potential. In this perspective, it is necessary to carry out feasibility studies of wind power generation projects, so that these become profitable and attractive investments, as well as addressing environmental concerns.

Therefore, Montes et al. [11] and Arnold and Yildiz [12], determine the detailed planning and analysis of the projects. According to the authors, these actions would maximize the profitability of the investment, as well as it would avoid the installation of unproductive wind farms, which would become obstacles to the short term development. In addition, Haufe and Ehrhart [13] emphasize that in order to eliminate excessive costs, many countries have implemented competition mechanisms, such as auctions. However, the auctions are sensitive to market structure, that is, they depend on the political and economic objectives of each region.

In this context, similar to studies such as Li et al. [14], Rocha et al. [3] and Ertürk [4], which perform the feasibility study of renewable energy generation projects, this present work applies the Monte Carlo Simulation method (MCS) in the project's investment analysis. However, differently from the mentioned articles, this paper uses the Artificial Neural Networks (ANN) in order to analyze the sensitivity of the feasibility in function of the project variables.

In general terms, this article aims to perform a sensitivity analysis in order to identify the variables that most influence the viability of wind power investment in small companies in Brazilian Northeast. For this, a stochastic economic viability analysis will be carried out and later ANN models will be applied to identify the most relevant variables.

\section{Theoretical Background}

\subsection{Economic Feasibility Analysis}

There are several methods that evaluate the financial feasibility of investments. However for analyzes of energy generation projects, the Net Present Value method (NPV) is widely used in literature as the main feasibility indicator $[4,12,14,15]$. In this sense, Hawawini and Viallet [16] affirm that NPV is a desirable decision criterion. In addition to other properties, it considers the expected cash flow of the 
project, taking in account its risks and being a measure of value creation. Therefore, when the result of the net present value is greater than zero the project creates value, that is, the investment is feasible.

For Ross et al. [17], NPV is a measure of value created or aggregated for an investment to be realized. In addition, the authors complement that the decisions made using the NPV criterion are defined, solely, based on the result, so that, when positive, the investment should be accepted. However, when the NPV is negative, it should be rejected.

The Net Present Value (NPV) is described by the following Equation (1):

$$
\mathrm{NPV}=-I+\sum_{j=1}^{n} \frac{C F_{j}}{(1+k)^{j^{\prime}}},
$$

where $C F_{j}$ represents the cash flow in period $j$ and $k$ indicates the minimum attractiveness rate, which represents the minimum return that the investor seeks to obtain in the investment; and $I$ is the investment.

According to Tao and Finenko [18], cash flow modeling considers money value throughout the project, where a discount rate is used to find the present value. Thus, the flow itself is formatted from the perspective of the developer, who in turn includes both client and investor.

In this case, the risk factors for the revenues from investing in renewable energy projects must be treated as random variables [14], so Monte Carlo Simulation can be used to calculate NPV, as suggested by Arnold and Yildiz [12]. It returns, through random simulations, a probabilistic model that presents the probability of feasibility of the project.

\subsection{Weighted Average Cost of Capital}

The weighted average cost of capital (WACC) is the method that calculates the rate of return of capital expected by investors applied in the cash flow of the project. Thus, the lower the weighted average cost of capital the higher the project value, since the discount rate reflects the opportunity cost in relation to the investment risk [16,18-20].

According to Ertürk [4] the WACC is calculated by Equation (2):

$$
\mathrm{WACC}=k_{e} E+k_{d} D(1-t),
$$

where $k_{e}$ represents the cost of equity (calculated preferably by Capital Asset Pricing Model-CAPM); $k_{d}$ is the cost of debt; $E$ represents the weight of equity in the investment (\%); $D$ denotes the weight of debt applied to the investment (\%); $t$ is the aliquot of the income tax.

It was noted that the majority of the publicly traded companies in the electricity sector have the proportion of $35 \%$ of equity and $65 \%$ of capital of debt. In this sense, it is fair to assign these values to variables and, respectively, in Equation (2) [21].

Furthermore, Aquila et al. [1] proposes the use of the interest rate of the National Development Bank (BNDES) in energy generation projects, which has a value of $11.33 \%$, so this value is attributed to the cost of debt $\left(k_{d}\right)$. In addition, it assumed $t$ as $34 \%$, in line with the current value of income taxes in Brazil.

Regarding the calculation of CAPM, the National Electric Energy Agency [22] suggests that a Brazilian risk factor is added so that the Brazilian market investor receives a risk premium. As it can be seen in Equation (3):

$$
k_{e}=R_{f}+\beta\left(R_{m}-R_{f}\right)+R_{b},
$$

where $R_{f}$ represents the risk-free rate (5.64\%); $R_{m}$ indicates the expected return of market $(13.20 \%)$; $R_{b}$ represents the risk premium Brazil (2.62\%) [22]; and $\beta$ denotes the levered beta (equity beta) and measures the project risk in regards to the market. 
In addition, to calculate the levered beta $(\beta)$ it was used the data of Damodaran [23], in which the renewable energy sector has the unlevered beta value of 0.69 . Using such data and considering the proportion of equity and debt, the levered beta of 1.54 is found through Equation (4):

$$
\beta_{a}=\beta_{d}\left[1+\frac{D}{E}(1-t)\right]
$$

where $\beta_{a}$ is the levered beta; $\beta_{d}$ is the unlevered beta; $D$ denotes the weight of debt applied to the investment (65\%); $E$ represents the weight of equity in the investment (35\%), and $t$ is the aliquot of the income tax.

\subsection{Artificial Neural Networks}

Artificial Neural Networks (ANNs) are computational structures that have as principle the representation of biological processes. These are composed of simple processing units and have the capacity to store experiments and make them available to the user [24,25].

Bigdeli et al. [26] state that Multi-Layer Perceptron (MLP) ANNs make up the model of artificial neural networks most commonly used in the literature. In this model, each unit calculates the scalar product of its input vector with the relative weight vector with each entry. When triggered, the value of the scalar product is used as a variable independent of an activation function, in which the dependent variable is the output of the neuron. However, it is known that the MLP supports more than one output in its mapping, since it does not have theoretical limitations on the data [27].

Figure 1 shows the architecture of an MLP network:

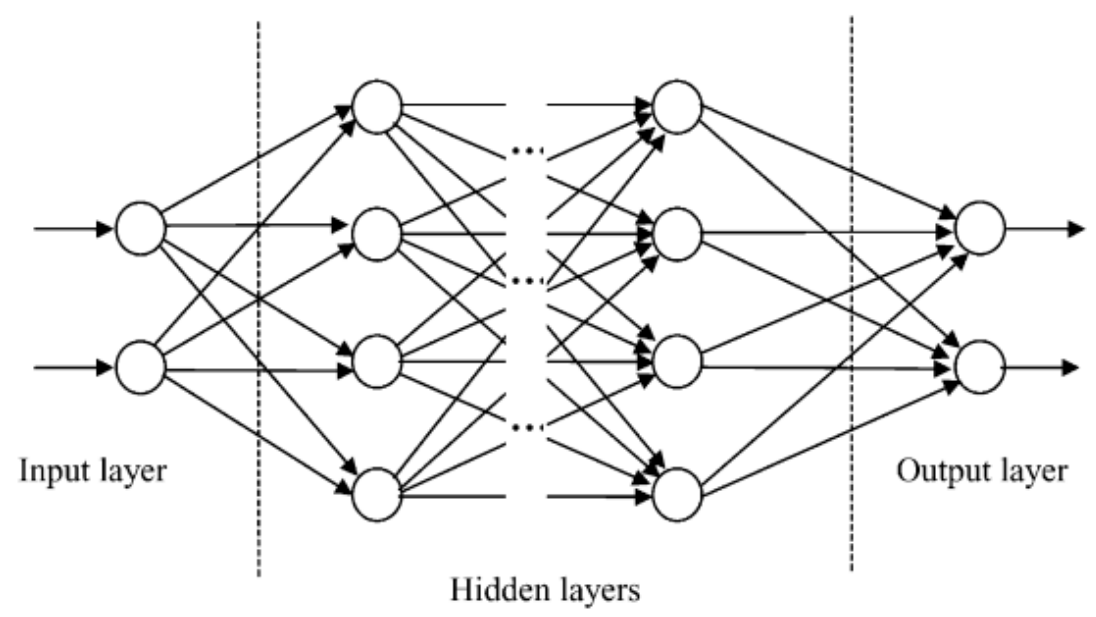

Figure 1. Representation of an MLP network. Adapted from ATA [28].

In this context, the backpropagation algorithm is widely used in the literature to carry out MLP network training, which seeks to learn and correct connection weights, as well as minimizing errors through activation threshold adjustments [27-29].

By designing a well-trained MLP network model $(m \times n \times 1)$, where $m$ is the number of nodes in the input layer, $n$ are the nodes of the hidden layer, and 1 is the output layer node, the relative importance of input variables can be calculated by Equation (5) [27,30]:

$$
R I_{i}=\frac{r_{i}}{\sum_{i=1}^{m}\left|r_{i}\right|} \times 100 \%
$$

For this calculation, Chakrabarty et al. [27] stipulate some steps that must be followed. These are:

- The vector, $M(1 \times n)$, must be organized with the interconnection weights between the nodes of the hidden layers $(n)$ and the nodes of the output layers; 
- The matrix, $W(m \times n)$, must be organized with the interconnection weights between the nodes of the input layers $(m)$ and the nodes of the hidden layers $(n)$;

- $\quad$ Calculate the vector $R=M W^{\mathrm{T}}$, where $R=\left[r_{1}, r_{2}, \ldots, r_{m}\right]$;

- Finally, we calculate the relative importance $\left(R I_{i}\right)$, in percentage, of each node $i$ of the input layer, as given by Equation (5).

After completing these steps, the relative importance $(R I)$ of each input parameter over the output variable is obtained, of which a sensitivity analysis of these variables will be performed.

\section{Materials and Methods}

This research is classified as applied in nature. Regarding the objectives, it is characterized as exploratory research, as to the way of approach is quantitative, as numerical data and calculations for the solution of the proposed problem was used. As for the research method, it is classified as a modeling and simulation research, since it tried to reproduce a real system through a computational model [31].

This work proposes to analyze the economic feasibility of an investment directed to the installation and production of electricity from wind power in a small business (SB). To exemplify this proposal, as Rocha et al. [3], a region with high wind speed of the Brazilian northeast was chosen and the wind speed behavior data collected [32]. The Weibull distribution is widely used in literature as the one that best suits the wind speed behavior as a function of time [33]. Thus, the Weibull distribution was employed with values for scale parameter $(C)$ and shape parameter $(k)$ equal to 7.0 and 3.0, respectively [32].

In this context, the investment is based on the purchase of a $30 \mathrm{~kW}$ wind turbine, power compatible with the need for a SB. Thus, after research among several companies that provide this type of product, giving priority to suppliers in the Northeast, it was stipulated $R \$ 408,950.00$ as the average value of the investment. The specifications of the wind turbine are: diameter of 13.2 meters and efficiency of $92 \%$. Furthermore, it was found that the useful life of this type of product is 20 years without maintenance, which is easily found on the market. Then, $5 \%$ was determined as depreciation rate, so it is considered that the wind turbine will be totally depreciated after the 20 years.

Rocha et al. [3] present a routine for energy production calculation for wind power generators, as follow. The probability density function of a Weibull distribution with two parameters is given by Equation (6):

$$
f(v)=\frac{k}{C}\left(\frac{v}{C}\right)^{k-1} e^{-\left(\frac{v}{C}\right)^{k}}
$$

where $v$ represents the wind speed $(\mathrm{m} / \mathrm{s}) ; k$ denotes the shape parameter; and $C$ represents the scale parameter $(\mathrm{m} / \mathrm{s})$.

Electric power in watts is a cubic function of wind speed (v) given by Equation (7):

$$
P=\frac{1}{2} \rho A_{r} v^{3} C_{P} \eta
$$

where $\rho$ represents the air density; $A_{r}$ stands for the area encompassed by the rotor $\left(\pi D^{2} / 4\right.$, where $D$ is the rotor diameter); $C_{P}$ represents the aerodynamic coefficient of rotor power; and $\eta$ denotes the efficiency of the generator-mechanical set and electric transmissions. The following values were considered for the current study: $\rho=1.225 \mathrm{~kg} / \mathrm{m}^{3} ; D=13.2 \mathrm{~m}$; and $\eta=0.92$. The $C_{P}$ for a wind power turbine varies with the wind speed, as follows [3]:

$$
C_{P}=-0.08114+0.1771 v-0.01539 v^{2}+0.00034 v^{3} .
$$


Finally, Equation (6) was used to calculate the annual energy production $(A E P)$ :

$$
A E P=8.76 \times \int_{v \min }^{v \max } P(v) f(v) d v(k W h),
$$

where $v$ is the wind speed; $P(v)$ is the power curve of the wind turbine; and $f(v)$ is the probability density function in relation to the wind speed.

According to ANEEL [22], taxes were disregarded, as renewable energy producers are exempt from taxes proportional to revenue. However, the financing rate was $11.33 \%$, in accordance with the financing conditions offered by BNDES [1].

According to Rocha et al. [34], in Brazil's net metering, customers who produce surplus energy through microgeneration systems are rewarded with one credit for each energy unit provided to the grid. The ratio between the credit and the price of the energy tariff used by the utilities, which is different in each state, is one-to-one. Considering the savings on electricity expenses that arise from the generated credits as income for the individual who invests in electric microgeneration, it is possible to apply the NPV for the economic feasibility analysis of this type of project.

Thus, in order to assign uncertainty to the project evaluation, a stochastic analysis was carried out through the execution of 10,000 simulations, through the Monte Carlo Simulation (MCS). Then, the sensitivity analysis was then performed in order to define which variables most affect the NPV. For this, the tools Microsoft Excel ${ }^{\circledR}$ and Crystal Ball ${ }^{\circledR}$ were used.

Finally, considering the results obtained by the simulations, these variables were used to train the MLP network and to calculate the relative importance of each input variable in relation to the output $(\mathrm{NPV})$. For this, were used the software Statistica ${ }^{\circledR}$ and Microsoft Excel ${ }^{\circledR}$. To execute the network training, we opted for the Automated Network Search (ANS) strategy, which seeks to identify the ideal parameters for model construction.

It is worth mentioning that the results obtained with the simulations were used for the network training, simply with the objective of identifying the relative importance of the variables. However, no predictions were made based on simulated data.

\section{Results and Discussion}

The project cash flow was elaborated based on the values and distributions according to Table 1 . Thus, the uncertainty was applied only in the variables of wind speed, investment and energy tariff, since the remaining ones were not shown to be relevant in the NPV or are calculated, as is the case of energy production.

Table 1. Representation of cash flow, its values and distributions.

\begin{tabular}{ccccc}
\hline Parameters & Distribution & Minimum & Probable & Maximum \\
\hline Wind speed & Weibull & & - & \\
Investment & Triangular & $\mathrm{R} \$ 368,055.00$ & $\mathrm{R} \$ 408,950.00$ & $\mathrm{R} \$ 449,845.00$ \\
Energy tariff & Triangular & $\mathrm{R} \$ 0.41$ & $\mathrm{R} \$ 0.45$ & $\mathrm{R} \$ 0.50$ \\
Period (years) & Fixed & & 20 & \\
Annual tariff & Fixed & & $2.30 \%$ & \\
readjustment & Fixed & - & $10.29 \%$ & - \\
WACC & Fixed & & $11.33 \%$ & \\
Financing rate & Fixed & & $5 \%$ & \\
Depreciation & Calculated & & - & \\
Energy production & C & & \\
\hline
\end{tabular}

For the electricity tariff, the data collected from the utility was used to compose the parameters of a triangular distribution, in which 0.50 and 0.41 are the largest and smallest values found, respectively, and 0.45 is the average of the values collected. In addition, in agreement with Holdermann et al. [15], it was attributed an annual tariff readjustment of $2.30 \%$ per year. 
Moreover, for the investment, as these are imported materials and that suffer variations of the exchange rate, a possible oscillation in the value of the investment of $R \$ 40,895.00$ was considered, i.e., $10 \%$ of the total investment. Given this, a triangular distribution was chosen, and the average of the quotations with suppliers was considered as the most probable value.

Furthermore, according to Figure 2, there is a probability of $28.65 \%$ of the NPV being greater than zero, i.e., a low probability of feasibility, which can be observed through the average NPV, in the amount of $\mathrm{R} \$-90,439.00$. Therefore, it can be concluded that investments in wind power generation may be viable in the Brazilian northeast, but this may not be attractive for investors, since in the scenario studied, there is still a lot of uncertainty and a low probability of viability, as well as in studies by Aquila et al. [7], Rocha et al. [3] and Holdermann et al. [15].

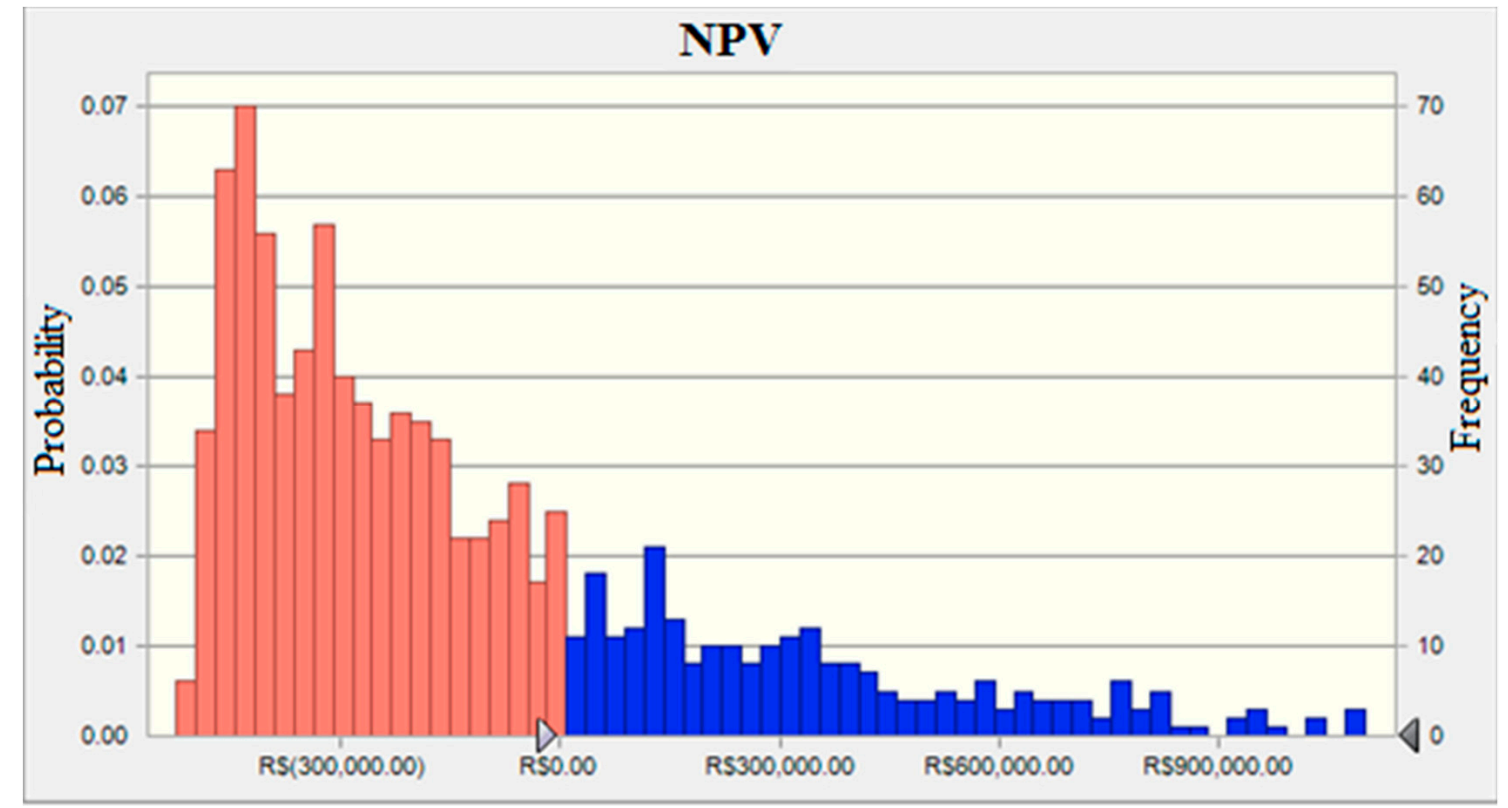

Figure 2. Probability of feasibility resulting from MCS.

In this sense, one should seek to know under which variables the NPV is more sensitive, for which two alternatives have been chosen.

The tornado chart (Figure 3), shows that wind speed is the variable that impacts the net present value (NPV) the most and, consequently, the viability of the project. Moreover, the value of the investment and the energy tariff, even if on a much smaller scale, show a significant value in the NPV, which are variables that are easier to adapt, since they are related to production costs, taxes, financing rates, among others. In this segment, the Brazilian government is fundamentally important, as it can promote types of monetary incentives for this type of project in order to make it more attractive and profitable. 


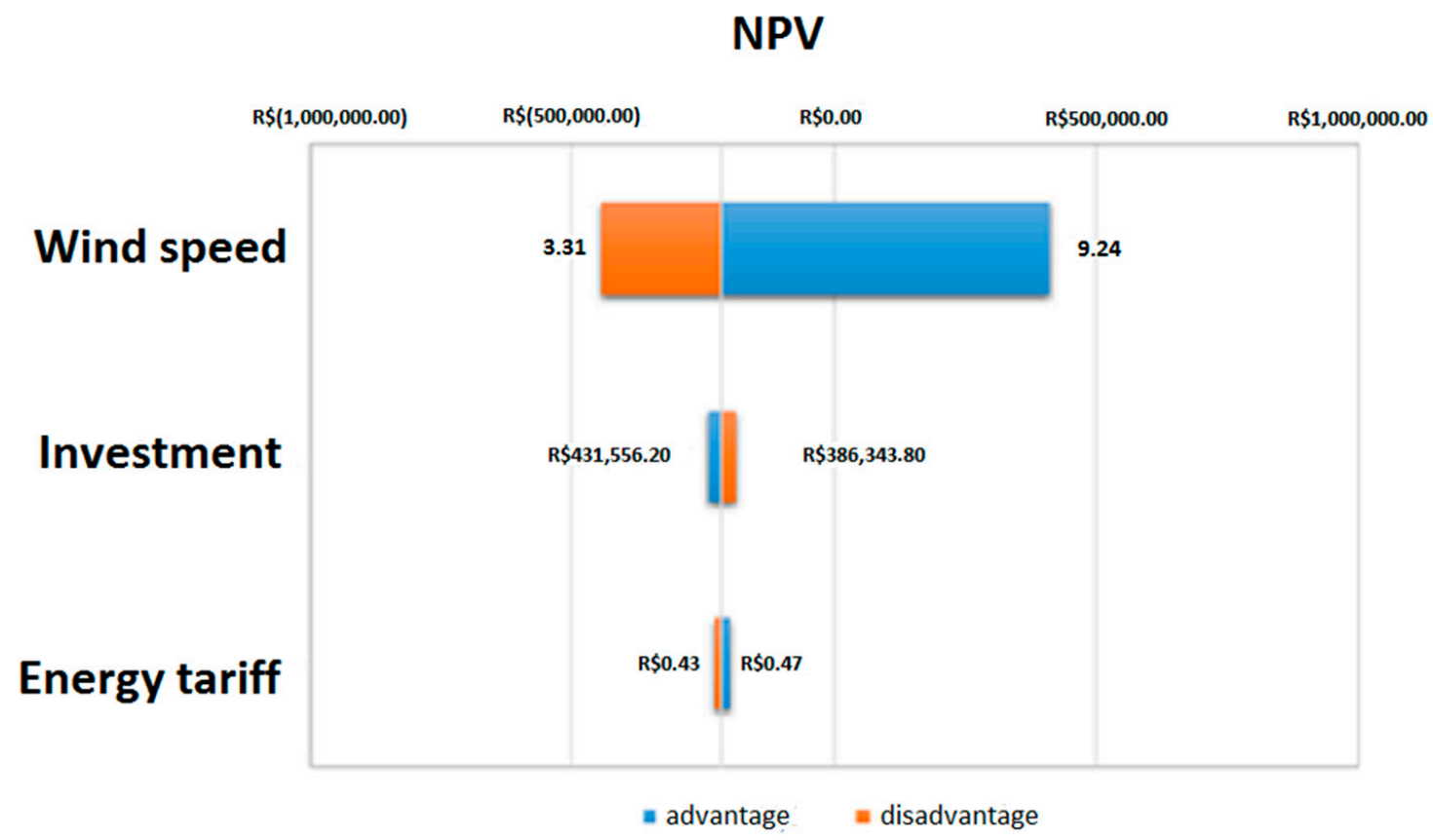

Figure 3. Tornado chart: sensitivity analysis.

In a second analysis, as previously reported, we opted for the Automated Network Search (ANS) strategy, which seeks to identify the ideal parameters for the ANN construction. Under these conditions, the structure identified with the lowest prediction error was the configuration MLP 3-5-1, that is, three is the number of nodes in the input layer, five are the nodes of the hidden layer, and one is the output layer node. In addition, the relative importance $(R I)$ of these variables through ANN was estimated (see Table 2 and Figure 4), and therefore, there is consonance about the importance of wind speed in the viability of the project. However, according to $R I$ results, the energy tariff was more important than the value of investment in impacting the NPV. Then, it can be concluded that the wind speed has great power of influence in the project. Finally, it should be noted that by calculating $R I$ it was possible to obtain a better discrimination of the variables.

Table 2. Representation of the Relative Importance (RI) of the parameters in the NPV value.

\begin{tabular}{cc}
\hline Parameters & Relative Importance (RI) \\
\hline Wind speed & $56.12 \%$ \\
Energy tariff & $27.51 \%$ \\
Investment & $16.37 \%$ \\
\hline
\end{tabular}

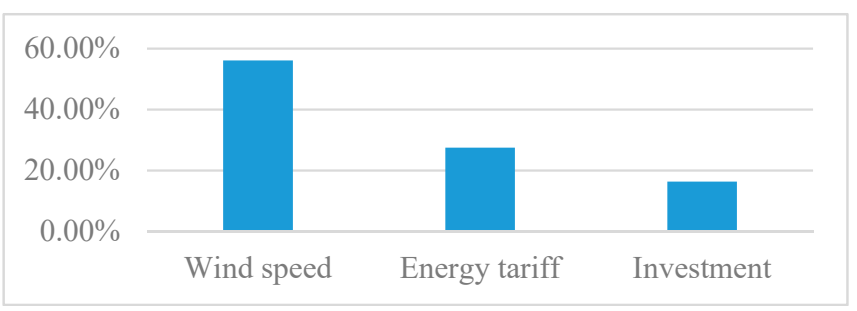

Figure 4. Relative importance $(R I)$ through ANN: variables that most impact the NPV.

\section{Conclusions}

In this work, an economic feasibility analysis of a project of electric power generation from wind power in an SB located in the northeast region was carried out. To better analyze the investment, it was decided to carry out the stochastic analysis of economic viability and to verify which variables have 
greater relative importance in the project. Therefore, conclusions showed that the wind speed has the main influence on the problem, followed by similar amounts between the cost of the investment and the energy tariff. Moreover, the relative importance analysis through ANN proved to be feasible, with good discrimination of the variables, being possible to rank them by the impact on NPV.

It can be inferred that because it is directly related to geographic issues, the wind speed is of difficulty adequacy, since it is totally inherent to the location of the project. As a result, it is concluded that this parameter is impossible to be controlled, but it is possible to elaborate forecast studies in order to anticipate the inherent uncertainties of the project. In addition, this result shows the importance of the site selection when projecting the installation of wind turbines.

It has been inferred that the energy tariff and the investment can make projects in wind energy more attractive, since these are directly related to government actions. Thus, programs of incentives for the production of clean energy that make cheaper the purchase of wind turbines and lower taxes and financing rates can make wind power more profitable and attractive.

Finally, this study presented a new systematics for conducting studies on the sensitivity of the variables to the NPV, using ANN. As recommendation for future studies, the application of the presented methodology in other operations is proposed. Furthermore, additional new questions should be investigated, such as identification of suitable locations, size of wind turbine, electrical grid stability and government policy measures.

Author Contributions: Conceptualization, P.R.J., L.C.S.R., and G.A.; methodology, G.A., P.R.J. and R.S.P.; software, E.F. and V.G.A.; validation, E.F., V.G.A. and L.S.L.; formal analysis, V.G.A. and E.F.; investigation, G.A., E.F. and V.G.A.; resources, P.R.J., R.S.P. and L.C.S.R.; data curation, E.F., V.G.A. and L.S.L.; writing-original draft preparation, E.F.; writing-review and editing, P.R.J. and L.C.S.R.; supervision, P.R.J. and R.S.P.; project administration, P.R.J.; funding acquisition, P.R.J. and R.S.P.

Funding: The authors would like to thanks CNPq and CAPES for their financial support and research incentive.

Conflicts of Interest: The authors declare no conflict of interest.

\section{References}

1. Aquila, G.; Rocha, L.C.S.; Junior, P.R.; Pamplona, E.O.; Queiroz, A.R.; Paiva, A.P. Wind power generation: An impact analysis of incentive strategies for cleaner energy provision in Brazil. J. Clean. Prod. 2016, 137, 1100-1108. [CrossRef]

2. Ringel, M. Fostering the use of renewable energies in the European Union: The race between feed-in tariffs and green certificates. Renew. Energy 2006, 31, 1-17. [CrossRef]

3. Rocha, L.C.; Aquila, G.; Junior, P.R.; Paiva, A.; Pamplona, E.; Balestrassi, P. A stochastic economic viability analysis of residential wind power generation in Brazil. Renew. Sustain. Energy Rev. 2018, 90, 412-419. [CrossRef]

4. Ertürk, M. The evaluation of feed-in tariff regulation of Turkey for onshore wind energy based on the economic analysis. Energy Policy 2012, 45, 359-367. [CrossRef]

5. Anoune, K.; Bouya, M.; Astito, A.; Ben Abdellah, A. Sizing methods and optimization techniques for PV-wind based hybrid renewable energy system: A review. Renew. Sustain. Energy Rev. 2018, 93, 652-673. [CrossRef]

6. Mohammadi, A.; Mehrpooya, M. A comprehensive review on coupling different types of electrolyzer to renewable energy sources. Energy 2018, 158, 632-655. [CrossRef]

7. Aquila, G.; Junior, P.R.; Pamplona, E.O.; Queiroz, A.R. Wind power feasibility analysis under uncertainty in the Brazilian electricity market. Energy Econ. 2017, 65, 127-136. [CrossRef]

8. Wong, S.; Bhattacharya, K.; Fuller, J.D. Long-Term Effects of Feed-in Tariffs and Carbon Taxes on Distribution Systems. IEEE Trans. Power Syst. 2010, 25, 1241-1253. [CrossRef]

9. Empresa de Pesquisa Energética (EPE). Avaliação da Geração de Usinas Hîbridas Eólico-Fotovoltaicas: Proposta Metodológica e Estudos de caso; EPE: Rio de Janeiro, Brazil, 2016; p. 32.

10. Silva, N.F.; Rosa, L.P.; Freitas, M.A.V.; Pereira, M.G. Wind energy in Brazil: From the power sector's expansion crisis model to the favorable environment. Renew. Sustain. Energy Rev. 2013, 22, 686-697. [CrossRef]

11. Montes, G.; Martin, E.; Bayo, J.; Garcia, J. The applicability of computer simulation using Monte Carlo techniques in windfarm profitability analysis. Renew. Sustain. Energy Rev. 2011, 15, 4746-4755. [CrossRef] 
12. Arnold, U.; Yildiz, Ö. Economic risk analysis of decentralized renewable energy infrastructures and a Monte Carlo Simulation approach. Renew. Energy 2015, 77, 227-239. [CrossRef]

13. Haufe, M.; Ehrhart, K. Auctions for renewable energy support-Suitability, design, and first lessons learned. Energy Policy 2018, 121, 217-224. [CrossRef]

14. Li, C.-B.; Lu, G.-S.; Wu, S. The investment risk analysis of wind power project in China. Renew. Energy 2013, 50, 481-487. [CrossRef]

15. Holdermann, C.; Kissel, J.; Beigel, J. Distributed photovoltaic generation in Brazil: An economic viability analysis of small-scale photovoltaic systems in the residential and commercial sectors. Energy Policy 2014, 67, 612-617. [CrossRef]

16. Hawawini, G.; Viallet, C. Finance for Executives: Managing for Value Creation, 4th ed.; South-Western Cengage Learning: Boston, MA, USA, 2009; pp. 190-334.

17. Ross, S.A.; Westerfield, R.W.; Jordan, B.D.; Lamb, R. Fundamentos de Administração Financeira, 9th ed.; Mcgraw-Hill AMGH: New York, NY, USA, 2013; pp. 280-438.

18. Tao, J.Y.; Finenko, A. Moving beyond LCOE: Impact of various financing methods on PV profitability for SIDS. Energy Policy 2016, 98, 749-758. [CrossRef]

19. Ross, S.A.; Westerfield, R.W.; Jordan, B.D. Fundamentals of Corporate Finance, 6th ed.; Mcgraw-Hill: New York, NY, USA, 2002; pp. 104-337.

20. Reichelstein, S.; Yorston, M. The prospects for cost competitive solar PV power. Energy Policy 2013, 55, 117-127. [CrossRef]

21. Bolsa de Valores, Mercadorias E Futuros. Available online: http://www.bmfbovespa.com.br/pt_br/ (accessed on 1 April 2018).

22. ANEEL. Nota Técnica $n^{\circ}$ 22/2015-SGT/ANEEL, de 29 de janeiro de 2015. 2015. Available online: http://www. aneel.gov.br/aplicacoes/audiencia/arquivo/2014/023/resultado/nt_22_2015_sgt_custo_de_capital.df (accessed on 5 April 2018).

23. Damodaran, A. Betas by Sector (US). January 2018. Available online: http://people.stern.nyu.edu/adamodar/ New_Home_Page/datafile/Betas.html (accessed on 1 December 2018).

24. Adya, M.; Collopy, F. How effective are Neural Networks at Forecasting and Prediction? A Review and Evaluation. J. Forecast. 1998, 17, 481-495. [CrossRef]

25. Haykin, S. Neural Networks and Learning Machines, 3rd ed.; Prentice Hall: Upper Saddle River, NJ, USA, 2009.

26. Bigdeli, N.; Afshar, K.; Gazafroudi, A.; Ramandi, M. A comparative study of optimal hybrid methods for wind power prediction in wind farm of Alberta, Canada. Renew. Sustain. Energy Rev. 2013, 27, 20-29. [CrossRef]

27. Chakrabarty, S.; Boksh, F.; Chakraborty, A. Economic viability of biogas and green self-employment opportunities. Renew. Sustain. Energy Rev. 2013, 28,757-766. [CrossRef]

28. Ata, R. Artificial neural networks applications in wind energy systems: A review. Renew. Sustain. Energy Rev. 2015, 49, 534-562. [CrossRef]

29. Zhang, G.; Patuwo, B.E.; Hu, M.Y. Forecasting with artificial neural networks: The state of the art. Int. J. Forecast. 1998, 14, 35-62. [CrossRef]

30. Costa, S.P.; Lima, F.R.; Lapa, C.M.F.; Mól, A.C.; Lira, C.A. The artificial neural network used in the study of sensitivities in the IRIS reactor pressurizer. Prog. Nucl. Energy 2013, 69, 64-70. [CrossRef]

31. Bertrand, J.; Fransoo, J. Operations Management research methodologies using quantitative modeling. Int. J. Oper. Prod. Manag. 2002, 22, 241-264. [CrossRef]

32. NASA. Power Data Access View. 2019. Available online: https://power.larc.nasa.gov/data-access-viewer/ (accessed on 10 January 2019).

33. Atlas do Potencial Eólico Brasileiro. 2001. Available online: http://www.cresesb.cepel.br/publicacoes/ download/atlas_eolico/Atlas\%20do\%20Potencial\%20Eolico\%20Brasiliro.pdf (accessed on 5 May 2018).

34. Rocha, L.C.S.; Aquila, G.; Pamplona, E.; Paiva, A.P.; Chieregatti, B.G.; Lima, J.S. Photovoltaic electricity production in Brazil: A stochastic economic viability analysis for small systems in the face of net metering and tax incentives. J. Clean. Prod. 2017, 168, 1448-1462. [CrossRef]

(C) 2019 by the authors. Licensee MDPI, Basel, Switzerland. This article is an open access article distributed under the terms and conditions of the Creative Commons Attribution (CC BY) license (http://creativecommons.org/licenses/by/4.0/). 